CASO DE ENSINO $\mid$ CASE STUDY

\title{
OPORTUNIDADE DE NEGÓCIO QUE VEM DO LIXO: CASO BRANCA RECICLÁVEIS
}

\section{INTRODUÇÃO}

Este é um Caso de Ensino sobre a Branca Recicláveis, uma empresa cearense cujas atividades principais são a compra e a venda de resíduos sólidos para reciclagem. Tal empresa foi fundada por necessidade, por uma empreendedora que iniciou a atividade em 1998, mas que, somente em 2006, pôde legalizar seu negócio, firmando-se no contexto do mercado brasileiro de recicláveis.

Em virtude da crescente industrialização, acompanhada do aumento e da alteração da composição do lixo de predominantemente biodegradável para uma maior quantidade de elementos de difícil degradação, os grandes grupos empresariais são recorrentemente apontados como vilões do meio

Fernanda Raquel

Gadelha

Bacharel em Administração Unichristus - Fortaleza-CEBR $<$ f_raquel1984@hotmail. com>

Raphael de Jesus

Campos de Andrade Mestre em Administração de Empresas - UECE e Analista da Federação das Indústrias do Estado do Ceará - FIEC Fortaleza-CE-BR $<$ raphaeldj. campos@gmail.com>

Laodicéia Amorim

Weersma

Doutoranda em Gestão de Empresas e Inovação Universidade de Coimbra - Portugal e professora da Unichristus - Fortaleza-CEBR<laoweersma@gmail. com $>$ ambiente e vêm sofrendo pressões do governo, da mídia e da sociedade para mitigar os impactos de suas operações, mas têm se fortalecido, em termos de credibilidade, perante suas partes interessadas, a partir de práticas de responsabilidade social e sustentabilidade.

Após cerca de 20 anos de discussões no Congresso Nacional sobre a questão dos resíduos sólidos, foi aprovada a Lei Federal no 12.305/2010 (BRASIL, 2010), que instituiu a Política Nacional de Resíduos Sólidos (PNRS) e foi sancionada em 02 de agosto de 2010. Essa iniciativa não é somente uma questão de regulamentação, mas uma visão estratégica para o setor produtivo, na medida em que estabelece responsabilidades compartilhadas entre fabricantes, importadores, distribuidores, comerciantes, consumidores e poder público pelo ciclo de vida dos produtos e pela gestão integrada dos resíduos sólidos.

Com vistas à prevenção e ao controle da poluição, à proteção e à recuperação da qualidade do meio ambiente e à promoção da saúde pública, a PNRS defende ainda que, na gestão dos resíduos sólidos, deve ser observada a seguinte ordem de prioridade: não geração, redução, reutilização, re- 
ciclagem, tratamento dos resíduos sólidos e disposição final ambientalmente adequada dos rejeitos.

Duas abordagens tratam da relação entre a regulamentação ambiental e a firma. A primeira perspectiva é ortodoxa e destaca a existência de um trade-off: de um lado os benefícios sociais decorrentes de uma maior preservação ambiental e, de outro lado, a elevação dos custos privados do setor produtivo, a elevação de preços e a resultante redução da competitividade.

A segunda flexibiliza esse trade-off e argumenta que as firmas podem responder às restrições decorrentes da regulamentação ambiental com novas configurações, em termo mais comum, com inovações, melhorando a competitividade.

Independente da abordagem, o fato é que o modelo de produção contemporâneo não coincide com os limites ambientais do planeta.

Talvez por isso o mercado de recicláveis, normalmente marginalizado por lidar com o que é considerado inservível e por empregar mão de obra desqualificada e socialmente vulnerável, tem crescido e se desenvolvido nos últimos anos, gerando valor para toda a cadeia produtiva.

Segundo o Instituto Brasileiro de Geografia e Estatística, a partir das Pesquisas Nacionais de Saneamento Básico (PNSB), em 1989, os vazadouros a céu aberto representavam 88,2\% dos destinos finais dos resíduos sólidos do país. Esse número caiu para $72,3 \%$ em 2000 e para 50,8\% em 2008. Por outro lado, existiam, respectivamente nos mesmos períodos, 58, 451 e 994 programas de coleta seletiva em operação no país.

A PNSB 2008 apontou que os municípios com serviço de coleta seletiva separam, prioritariamente, papel e/ou papelão, plástico, vidro e metal (materiais ferrosos e não ferrosos), sendo os mesmos assim negociados: comerciantes de recicláveis, como principais receptores finais desses materiais, com 53,9\%; indústrias recicladoras, 19,4\%; entidades beneficentes, 12,1\%; e outras entidades, $18,3 \%$.

São números que reafirmam o crescimento e desenvolvimento do mercado de recicláveis e que implicam, por um lado, em novas oportunidades de negócios, mas, por outro, em aumento de competição por tais oportunidades, exigindo dos competidores novas estratégias competitivas.

Os comerciantes de recicláveis, também conhecidos como deposeiros ou sucateiros, como é o caso da Branca Recicláveis, enfrentam ainda outro desafio: o estigma social de explorarem o trabalho dos catadores, que, não sendo capazes de produzir em escala, vendem suas mercadorias por preços irrisórios. A própria indústria recicladora estimula a ação dos comerciantes em detrimento dos catadores, de modo a garantir a disponibilidade de quantidade e qualidade do material para reciclagem.

Quais, então, as experiências e características da Branca Recicláveis e como ela se diferencia e inova (ou não) em um mercado recém-regulamentado, em expansão, hipercompetitivo e associado a condições extremas e de vulnerabilidade social?

É o que se pretende refletir a partir dos capítulos seguintes.

\section{O MERCADO BRASILEIRO DE RECICLÁVEIS}

Segundo um estudo realizado em 2010 pelas universidades norte-americanas de Yale e Columbia, o Brasil, em um ranking de 163 países, ocupa o 62 lugar 
em desempenho ambiental, tendo em vista categorias como saúde ambiental, qualidade do ar, gestão da água, biodiversidade e habitat, florestas, pesca, agricultura e mudanças climáticas.

O Brasil também ocupa, em comparação com os demais países, posição intermediária, no que tange ao gerenciamento de seus resíduos sólidos que, embora coletados, não recebem a devida destinação, sendo depositados na maior parte das vezes em vazadouros a céu aberto ou lixões, que já somam 2.906 unidades, distribuídas por 2.810 municípios (MARCHI, 2011).

A coleta seletiva é praticada em $56,9 \%$ dos municípios brasileiros, mas se resume a pontos de entrega voluntária ou a convênios entre cooperativas de catadores e poder público para a execução desses serviços (BRASIL, 2014).

O custo de oportunidade decorrente da não reciclagem de resíduos no país é estimado em oito bilhões de reais por ano (PORTAL BRASIL, 2012).

Mesmo não sendo, portanto, referência nos cuidados ao meio ambiente em geral e aos resíduos sólidos em particular, o Brasil ainda é considerado um "credor ecológico", pois possui mais recursos naturais do que consome, podendo até exportar sua biocapacidade para países devedores.

$\mathrm{O}$ índice nacional de $11 \%$ de reciclagem e compostagem é superior ao da República Tcheca, de Portugal, da Argentina, da Colômbia e da Hungria e próximo ao do Reino Unido (BARBOSA, 2012).

Outro ponto que destacou o Brasil em relação ao restante do mundo foi, em 2010, a sanção da Política Nacional de Resíduos Sólidos (PNRS), objeto da Lei 12.305/2010 (BRASIL, 2010), que defende como ideia central que a vida útil dos produtos não termina após seu consumo e preconiza o compartilhamento das responsabilidades pela coleta, tratamento e destinação final entre poder público, setor produtivo e consumidores.

Ações como elaboração de estudos para a regionalização, por meio de planos estaduais, municipais e intermunicipais de gestão integrada de resíduos sólidos, apoio e incentivo à formação de consórcios públicos e estímulo à formação de cooperativas atuantes no setor de triagem e reciclagem, caracterizam parte do rol de diretrizes da PNRS. (DEMAJOROVIC; MIGLIANO, 2013).

A Lei instituiu também o mecanismo de logística reversa com visas a reciclar, reinserir e reaproveitar os resíduos na cadeia produtiva, provendo a disposição ambientalmente adequada dos rejeitos finais desses processos e promovendo a inserção social de grupos de catadores.

A principal questão da logística reversa é o equacionamento dos caminhos percorridos pelos bens ou seus materiais constituintes após o término de sua vida útil. Esses bens ou materiais se transformam em produtos denominados de pós-consumo e podem ser enviados a destinos finais tradicionais, tais como incineração ou aterros sanitários, ou retornar ao ciclo produtivo, por meio dos canais do desmanche, da reciclagem ou do reuso, com o propósito de assegurar uma recuperação ambiental e recapturar valores econômicos (SOUZA, M.; PAULA; SOUZA, P., 2012).

Para tanto, as redes logísticas devem ser redesenhadas para facilitar o retorno dos produtos e a reutilização dessas peças e componentes no processamento da remanufatura (LEITE, 2003).

O reconhecimento da necessidade da responsabilidade compartilhada, tornada obrigatória pela PNRS, é essencial para o avanço da gestão de resíduos no país, pois a destinação adequada depende do traba- 
lho de todos os atores envolvidos na cadeia produtiva (HEBER; SILVA, 2014).

Se bem-sucedida, a PNRS pode contribuir para a diminuição da disposição incorreta de resíduos, para o aumento da vida útil dos aterros sanitários, para a diminuição da extração de matéria-prima virgem, para a redução do gasto de energia, para a melhoria das condições de trabalho de cata- dores cooperados, dentre outros benefícios. Alguns exemplos de práticas sustentáveis no Brasil merecem, portanto, ser citados para que outras empresas possam se inspirar e, assim, contribuir para a gestão integrada de resíduos sólidos.

O Quadro 1, abaixo, apresenta tais exemplos.

\begin{tabular}{|c|c|}
\hline Empresa & Práticas Sustentáveis \\
\hline $\begin{array}{l}\text { Hewlett-Packard } \\
\text { (HP) }\end{array}$ & $\begin{array}{l}\text { A HP teve como objetivo para o ano de } 2010 \text { a redução de } 25 \% \text {, em comparação } \\
\text { com os níveis de } 2005 \text {, no consumo combinado de energia e nas emissões } \\
\text { de gases que provocam o efeito estufa associados a suas operações e a seus } \\
\text { produtos. No que se refere à redução de dejetos e à reciclagem, a HP reservou } \\
\text { uma sala de cerca de } 40 \mathrm{~m} 2 \text { no piso térreo de sua fábrica em Sorocaba, no } \\
\text { interior de São Paulo. Lá são reciclados os cartuchos devolvidos pelos } \\
\text { consumidores em diversos pontos de coleta do país. Mais de trezentos e setenta } \\
\text { e cinco mil cartuchos já foram reciclados. O processo, em três etapas, consiste } \\
\text { na desmontagem, na separação de materiais não recicláveis, como a tinta } \\
\text { remanescente, e na logística reversa do plástico, que é moído e transformado } \\
\text { em placas que servem como insumo de peças instaladas na parte interna de } \\
\text { impressoras. A empresa afirma que hoje, em média, } 85 \% \text { dos componentes de } \\
\text { suas impressoras mais modernas são constituídos de material reciclado. }\end{array}$ \\
\hline AmBev & $\begin{array}{l}\text { Cerca de } 70 \% \text { da cerveja vendida pela AmBev é sob a forma de garrafas } \\
\text { retornáveis de plástico e de vidro. Os rótulos das embalagens são reciclados } \\
\text { e a celulose resultante é usada na produção de papelão. As cascas do malte, o } \\
\text { extrato de levedura e outros produtos decorrentes da fermentação são usados na } \\
\text { alimentação de animais, na criação de peixes e na indústria de laticínios. }\end{array}$ \\
\hline Coca-Cola & $\begin{array}{l}\text { Em março de 2010, em São Paulo, a Coca-Cola lançou o Plantbottle, uma } \\
\text { garrafa feita de PET na qual o etanol da cana-de-açúcar substitui parte do } \\
\text { petróleo utilizado como insumo. Os resíduos das embalagens são triturados e } \\
\text { passam por um processo de limpeza. O material é derretido e misturado a uma } \\
\text { nova resina, produzindo os recipientes que retornarão ao mercado. A tecnologia } \\
\text { já estava disponível na Alemanha e nos países nórdicos há quase } 10 \text { anos, mas } \\
\text { foi aplicada de forma pioneira no Brasil. A iniciativa reduz em até } 25 \% \text { as } \\
\text { emissões de CO2 da empresa. }\end{array}$ \\
\hline $\begin{array}{l}\text { Whirlpool (Brastemp } \\
\text { e Consul) }\end{array}$ & $\begin{array}{l}\text { Desde 2005, a Whirlpool (Brastemp e Consul) dispõe de um programa } \\
\text { experimental de coleta e reciclagem de geladeiras antigas. As peças usadas são } \\
\text { removidas e seguem para uma linha de desmontagem na fábrica da empresa, } \\
\text { em Joinville, em Santa Catarina. Além disso, uma parte das embalagens dos } \\
\text { produtos da empresa é coletada por meio de uma parceria com uma empresa } \\
\text { de varejo paulista: seus entregadores, quando levam os produtos novos à casa } \\
\text { do cliente, retiram a embalagem. Esta prática já produziu o recolhimento de } \\
\text { aproximadamente } 127 \text { toneladas de papelão, plástico e isopor. }\end{array}$ \\
\hline
\end{tabular}




\begin{tabular}{|l|l|}
\hline TetraPak & $\begin{array}{l}\text { Muitos funcionários da TetraPak, empresa especializada no envase de } \\
\text { alimentos, são incentivados a fazer mestrado e doutorado em universidades e } \\
\text { centros de pesquisa para que produzam tecnologias para a reciclagem de seus } \\
\text { produtos, constituídos por fibras, plástico e alumínio. As fibras são hidratadas, } \\
\text { separadas do plástico e do alumínio e utilizadas para a produção de papelão, } \\
\text { tubetes ou material gráfico para a própria empresa. O plástico é encaminhado } \\
\text { a empresas recicladoras e serve como matéria-prima para diversos produtos, } \\
\text { como cabos de vassoura, coletores etc. O alumínio é transformado em chapas } \\
\text { para fabricação de divisórias, móveis, peças decorativas e telhas, bem como em } \\
\text { lingotes para a produção de novas embalagens. }\end{array}$ \\
\hline Pão de Açúcar & $\begin{array}{l}\text { O Pão de Açúcar foi o primeiro grupo varejista brasileiro a disponibilizar } \\
\text { pontos de entrega voluntária de materiais recicláveis em suas lojas. Foram } \\
\text { instaladas, em parceria com a empresa Unilever, estações de reciclagem em } \\
\text { 110 lojas do grupo, distribuídas por 30 municípios brasileiros. Somente em } \\
\text { 2009, sete mil toneladas de recicláveis foram coletadas. Em 2007, foi criado } \\
\text { o Programa Caixa Verde, que oferece ao cliente a possibilidade de descartar } \\
\text { em urnas especiais, no momento em que passa pelo caixa, suas embalagens de } \\
\text { papel e plástico livres de resíduos de alimentos. Estes materiais são doados a 33 } \\
\text { cooperativas de catadores. }\end{array}$ \\
\hline
\end{tabular}

Quadro 1 - Exemplos de práticas sustentáveis de empresas no Brasil.

Fonte: adaptado de Marchi (2011).

As iniciativas não se restringem somente ao setor produtivo, mas são empreendidas também pelo poder público, terceiro setor, associações de classe, dentre outras (BRASIL, 2012).

A Federação das Indústrias do Estado de São Paulo - FIESP, por meio da Câmara Ambiental da Indústria Paulista - CAIP, vem discutindo acordos setoriais para o estabelecimento da logística reversa para produtos especiais.

Uma das inovações em pauta preconiza que algumas empresas, ao invés de investirem na coleta e no processamento das embalagens de seus produtos descartadas pós-consumo, podem obter créditos de outras que já praticam a logística reversa, à semelhança da prática internacional de compra de créditos de carbono (MARCHI, 2011).

O Ministério do Trabalho e Emprego (MTE) publicou, em 2012, a agenda de direitos e cidadania para prover a remediação e o encerramento de 358 lixões até 2014 e de mais 202 até 2015, como também lançou os programas "Recicla Brasil", para promover a logística reversa nos municípios, e "Pró-Catador", para garantir a inclusão social e produtiva dos catadores de materiais recicláveis (BRASIL, 2014). Nenhum programa voltado diretamente para os sucateiros, no entanto, foram até hoje elaborados.

Todavia, o poder público não possui a capilaridade necessária para recolher e reciclar todo o lixo produzido, mesmo após as determinações da Política Nacional de Resíduos Sólidos, fato que gera oportunidades de negócios para o setor privado (MAIA, 2013).

No Ceará, vários empregos são gerados com a atividade de reciclagem (CALDAS, 2008). Segundo o Sindicato das Empresas de Reciclagem de Resíduos Sólidos Domésticos e Industriais no Estado do Ceará - Sindiverde (2013), 85 empresas filiadas geram 1.800 empregos diretos. Cerca 
de $5 \%$ do lixo coletado em Fortaleza se transformam todos os meses em milhões de reais distribuídos entre catadores, sucateiros e indústrias.

Nessa perspectiva, o capítulo a seguir apresenta resumidamente a história da empresa Branca Recicláveis, posicionada como sucateira na cadeia de valor da reciclagem.

\section{A BRANCA RECICLÁVEIS}

A Branca Recicláveis é uma microempresa familiar que opera desde 1998 na cidade de Fortaleza, no Ceará, com o comércio de materiais recicláveis, tais como ferrosos, alumínios, cobres, papéis, plásticos, garrafas PET, vidros, baterias de veículos e lixo eletrônico.

Quanto aos propósitos estratégicos, destacam-se a missão, que é "comercializar resíduos sólidos passíveis de reciclagem, contribuindo com o meio ambiente e gerando recursos para a empresa", e a visão, que é "ser a empresa com maior faturamento por metro quadrado na comercialização de ferro e plástico do tipo PET da cidade de Fortaleza".

Destacam-se também os valores, que estão pautados na honestidade, na gentileza e no preço justo, que geram propaganda espontânea positiva para o negócio por parte de clientes e fornecedores, e na higiene, muito importante para o desempenho organizacional, pois evita insetos, roedores e consequentemente doenças que possam afetar funcionários e comunidade do entorno.

Os dados sobre a empresa foram coletados a partir de entrevistas semiestruturadas com a Dona Branca, uma senhora de 65 anos que já fora vendedora de um gran- de magazine, gerente de uma lavanderia e vendedora de uma loja de moda feminina, estando desempregada antes de decidir montar o seu próprio negócio no setor de reciclagem de resíduos sólidos.

O empreendimento decorreu da necessidade da empresária de pagar o aluguel de sua residência e por incentivo de sua irmã e de seu cunhado, não estando inicialmente relacionado à percepção de algum tipo de oportunidade de negócio e só formalizado como Micro Empreendimento Individual - MEI em 2006.

A Branca Recicláveis, no entanto, foi desenvolvendo e criando o seu espaço no mercado a partir da fidelização de fornecedores de materiais recicláveis, como condomínios residenciais e oficinas mecânicas da circunvizinhança, e de mão de obra comprometida - "carroceiros" (catadores) que praticam a coleta seletiva em até três bairros próximos, com carrinhos emprestados, feitos com geladeiras e pneus de veículos descartados.

Os produtos que geram maior renda para a empresa são o ferro e o papelão que, embora não tenham preços de revenda superiores a outros produtos, são coletados em maior volume, por conta da dinâmica do comércio e da parceria com as oficinas mecânicas do entorno, alcançando altos giros de estoque e volumes de venda; segundo a Dona Branca, oito toneladas de cada um desses produtos são revendidas mensalmente.

Nota-se que o entorno da Branca Recicláveis não tem um comércio dinâmico por acaso, especialmente no tocante às oficinas mecânicas, que já somam mais de 15 estabelecimentos. Existem nas suas proximidades duas lojas de uma grande empresa de peças automotivas, que vendem no varejo e no atacado e irradiam seu poder 
econômico para a cadeia produtiva, atraindo, assim, as oficinas mecânicas e, no ciclo reverso, a Branca Recicláveis.

Os condomínios também são grandes parceiros da empresa, que orienta os síndicos a incentivarem os moradores na prática da coleta seletiva. Um funcionário de cada condomínio fica responsável por reunir e vender o material reciclável para a Branca Recicláveis um dia antes da coleta tradicional de lixo. Os recursos obtidos pelos condomínios são utilizados na melhoria dos jardins, na compra de materiais de limpeza, no "caixinha de natal" dos funcionários, dentre outros benefícios - argumenta a Dona Branca.

Destacam-se também dois supermercados parceiros, que semanalmente vendem para a Branca Recicláveis as caixas de papelão e os sacos de embalagens utilizados pelas transportadoras.

Os materiais comprados são vendidos para indústrias recicladoras; os materiais mais volumosos, que não cabem no espaço físico da empresa, são vendidos para sucateiros de maior porte, que revendem para as indústrias recicladoras. Mas não se trata de uma tarefa simples e de fácil sucesso, conforme aponta o capítulo a seguir.

\section{OS DESAFIOS DE MERCADO}

Especialmente a partir de 2011, apesar dos acessos privilegiados a materiais recicláveis advindos das relações de confiança estabelecidas por Dona Branca ao longo do tempo, a empresa aprofunda suas dificuldades de gestão, competitividade e desempenho.

Os potenciais e, em menor medida, os atuais fornecedores da empresa, na perspectiva de aumentar seus ganhos e de aten- der sistematicamente à Política Nacional de Resíduos Sólidos, buscam vender seus resíduos para as indústrias recicladoras, diretamente.

Os "carroceiros", mesmo sendo pessoalmente próximos à Dona Branca, trabalham quando lhes convém e produzem o que acreditam lhes ser necessário. Como não há vínculo empregatício entre catador e sucateiro, não há como cobrar por produção.

O contexto de fornecimento do setor, portanto, constante e facilmente implica em queda de produtividade para a Branca Recicláveis.

Por outro lado, as indústrias recicladoras, normalmente por excesso de estoque e/ou de oferta, têm reduzido suas demandas por materiais recicláveis, transformando os sucateiros e os catadores, os elos mais frágeis da cadeia produtiva, em reféns de suas políticas de preços.

Além disso, a Branca Recicláveis possui na sua área de atuação um concorrente direto de maior porte e com política de preços mais agressiva, que assume, entretanto, maiores riscos de estocagem e de segurança.

Apesar de indireto, outro grande concorrente da Dona Branca é a Companhia de Energia do Estado do Ceará - COELCE, que, por meio do Programa Ecoelce, troca materiais recicláveis entregues em seus pontos de coleta por descontos na conta de energia. Iniciado em 2007, o programa tem 423 mil cadastrados e 62 pontos de coleta distribuídos por 28 municípios do Estado do Ceará (COELCE, 2014).

Outros sucateiros vêm adentrando o mercado sem se deparar com barreiras de entrada e apresentando, inclusive, diferenciais competitivos.

Tem-se ainda a legislação pertinente 
que, por ser recém-criada e ao defender a gestão compartilhada dos resíduos sólidos a partir da logística reversa, ainda não aponta, em termos práticos, se o papel do atravessador na cadeia da reciclagem é de parceiro ou de vilão e se deve, então, ser promovido ou eliminado.

As políticas públicas até então decorrentes da PNRS se concentram na eliminação dos lixões nos municípios e no desenvolvimento dos catadores por meio de cooperativas, mas ainda não se direcionaram para os dilemas dos sucateiros.

Em termos ideais, espera-se, portanto, que os fluxos reversos de materiais ocorram somente entre indústrias; ou se quer distribuir qualificação e valor para todos os atores da cadeia, incluindo catadores e sucateiros?

Diante de tais dilemas e desafios, os sucateiros em geral e a Branca Recicláveis em particular, em curto prazo, têm apenas dois caminhos naturais a percorrer: acumular prejuízos com as vendas de materiais recicláveis ou manter grandes estoques até que os preços subam novamente até patamares que permitam o lucro, consumindo, de uma forma ou de outra, suas reservas de capital.

Quais estratégias ou inovações a Branca Recicláveis pode (ou não) empreender para superar suas dificuldades? Este é o tema do capítulo a seguir.

\section{ESTRATÉGIAS COMPETITIVAS}

Dona Branca sempre sentiu a necessidade de profissionalizar a gestão de seu negócio que, como tantos outros empreendimentos no Brasil, nasceu de forma intuitiva, por necessidade, e não em função de uma visão de futuro ou da percepção de uma oportunidade de negócio.

Diante dos novos desafios e do desejo de descobrir caminhos alternativos para o sucesso, Dona Branca buscou crédito junto a instituições como Banco do Brasil, que tem linhas especiais para microempresas, e Banco do Nordeste (2014), que possui programas de financiamento para promoção do meio ambiente.

Os recursos obtidos foram utilizados para:

a) cobrir os prejuízos já acumulados com as vendas e com os estoques de materiais recicláveis;

b) prospectar novas indústrias recicladoras que pratiquem melhores preços de compra desses materiais;

c) adquirir o imóvel onde opera e aumentar sua capacidade de armazenamento e;

d) financiar pesquisa sobre a concorrência realizada pela própria empresa.

Os prejuízos acumulados foram realmente sanados, mas, nos meses subsequentes, as parcelas dos empréstimos mantiveram a empresa em dificuldades de honrar com seus compromissos financeiros.

As indústrias recicladoras que melhor pagavam por materiais recicláveis encontradas ficavam distantes o suficiente para aumentar os custos logísticos para além dos aumentos nas receitas. A empresa, de fato, adquiriu o imóvel onde opera e ampliou sua capacidade de armazenamento que, no entanto, ficou ociosa em $30 \%$, devido a sucessivas quedas no fornecimento de materiais recicláveis.

Quanto à pesquisa sobre a concorrência, foi possível averiguar que os outros sucateiros têm adquirido veículos de grande porte para efetuar suas coletas, além de 
atuarem no estilo "corpo a corpo" junto aos grandes fornecedores, oferecendo e realizando, eles mesmos, os serviços de coleta seletiva.

As quedas no fornecimento e o aumento da concorrência se apresentaram como as principais mudanças na dinâmica do setor, ocasionadas diretamente pela Política Nacional de Resíduos Sólidos. Parte dos potenciais e dos atuais fornecedores da Branca Recicláveis, na expectativa de atender à Lei, buscou por formas mais sistemáticas de reciclagem, dentre elas a comercialização direta com as indústrias recicladoras.

Para sobreviver, os sucateiros concorrentes, por sua vez, buscaram por inovações e novas formas de agregar valor, tornando-se, assim, mais competitivos (que a Branca Recicláveis, inclusive).

Estima-se que tais iniciativas das empresas geradoras e sucateiras fortaleçam ainda mais as indústrias recicladoras na cadeia produtiva, na medida em que contribuem para o aumento da oferta de materiais recicláveis de qualidade.

Dona Branca, adepta de uma gestão pouco agressiva, que "não mexe em time que está ganhando", reconhece, então, que errou ao pensar que os fornecedores permaneceriam fiéis a ela somente por conta do bom relacionamento pessoal.

Sem muitas alternativas, a empresa Branca Recicláveis tem participado de feiras e eventos de reciclagem na expectativa de conhecer inovações que possam reverter sua atual situação.

\section{NOTAS DE ENSINO}

\section{RESUMO}

Este é um Caso de Ensino sobre a Branca Recicláveis, uma empresa cearense cujas atividades principais são a compra e a venda de resíduos sólidos para reciclagem. Trata-se de um segmento regulamentado pela Política Nacional de Resíduos Sólidos, que estabelece responsabilidades compartilhadas entre fabricantes, importadores, distribuidores, comerciantes, consumidores e poder público pelo ciclo de vida dos produtos. Duas abordagens tratam da relação entre a regulamentação ambiental e a firma. A primeira destaca a existência de um trade-off entre os benefícios sociais decorrentes de uma maior preservação ambiental e a elevação dos custos privados do setor produtivo, a elevação de preços e a resultante redução da competitividade. A segunda flexibiliza esse trade-off e argumenta que as firmas podem responder às restrições decorrentes da regulamentação ambiental com inovações, melhorando a competitividade. O fato é que o modelo de produção contemporâneo não coincide com os limites ambientais do planeta. Talvez por isso, o mercado de recicláveis, marginalizado por lidar com o que é considerado inservível e por empregar mão de obra desqualificada e socialmente vulnerável, tem se desenvolvido nos últimos anos, gerando valor para toda a cadeia produtiva. Quais, então, as experiências e características da Branca Recicláveis e como ela se diferencia e inova (ou não) em um mercado regulamentado, em expansão, hipercompetitivo e associado a condições extremas? 
Palavras-chave: Reciclagem. Logística reversa. Política Nacional de Resíduos Sólidos.

\section{BUSINESS OPPORTUNITY IN WASTE RECYCLING: THE CASE OF BRANCA RECICLÁVEIS}

\section{SUMMARY}

This is a Teaching Case on Branca Recicláveis, a company from Ceará whose main activity is the purchase and sale of solid waste for recycling, a segment currently regulated by the National Solid Waste Policy, which establishes shared responsibility among manufacturers, importers, distributors, traders, consumers and government of the product life cycle and an integrated solid waste management. Two approaches deal with the relationship between the environmental regulation and the company. The first perspective is orthodox and highlights the existence of a trade-off: on one hand the social benefits of greater environmental protection and, on the other hand, the increasing costs of private productive sector, the rise in prices and the resulting reduction in competitiveness. The second makes this trade-off more flexible and argues that companies can respond to the constraints arising from environmental regulations with new settings, in more common term, with innovations, improving competitiveness. Regardless the approach, the fact is that the model of contemporary production does not coincide with the environmental limits of the planet. Perhaps this is why the market for recyclables typically marginalized for dealing with what is considered unserviceable and for employing unskilled labor and socially vulnerable people, has grown and developed in recent years, generating values for the entire production chain. So, what are the experiences and characteristics of the Branca Recicláveis and in what way it is differentiated and innovative (or not) in a newly regulated, expanding and hypercompetitive market associated with extreme conditions and social vulnerability?

Keywords: Recycling. Reverse logistics. National Solid Waste Policy.

\section{OBJETIVOS EDUCACIONAIS}

Pretende-se que os alunos sejam capazes de:

a) avaliar as consequências do modelo de produção atual de bens de consumo sobre o meio ambiente;

b) analisar a pertinência, os limites e os efeitos da intervenção do Estado sobre a economia;

c) avaliar a aderência da Política Nacional de Resíduos Sólidos aos atuais desafios de preservação do meio ambiente e do setor de reciclagem;

d) caracterizar a cadeia produtiva da reciclagem e sua atual dinâmica socioeconômica;

e) analisar as estratégias competitivas das organizações em função do contexto competitivo em que estão inseridas e;

f) traçar alternativas estratégicas para a Branca Recicláveis no atual contexto do mercado brasileiro de reciclagem.

Este caso pode ser usado em cursos de graduação e pós-graduação, bem como 
em programas de formação de empreendedores e treinamento de executivos, em disciplinas avançadas de Economia Empresarial, Gestão Estratégica, Gestão Ambiental, Logística, Marketing, Ética Empresarial e Responsabilidade Socioambiental.

\section{QUESTÕES PARA DISCUSSÃO}

a) Existe compatibilidade entre o atual modelo de produção industrial e a disponibilidade limitada de recursos naturais? Quais alternativas podem ser consideradas?

b) Existe um trade-off entre regulamentação ambiental e competitividade empresarial ou as empresas se reconfiguram diante das imposições legais, garantindo seus altos retornos?

c) Quais os principais impactos gerados pela Política Nacional de Resíduos Sólidos sobre a dinâmica socioeconômica do setor de reciclagem brasileiro?

d) Como se estrutura a cadeia produtiva da reciclagem no Brasil? Quais os seus principais atores e desafios respectivos?

e) Qual o papel do atravessador na cadeia produtiva da reciclagem? Qual sua relação com o catador? Quais as contribuições da PNRS nesse aspecto?

f) Quais os recursos internos e as competências essenciais da empresa Branca Recicláveis?

g) Quais os principais desafios de mercado por ela enfrentados?

h) Quais estratégias competitivas foram por ela formuladas para lidar com tais desafios? i) Quais resultados foram por ela obtidos a partir da implantação de tais estratégias?

j) Quais estratégias alternativas poderiam ter sido empreendidas para o alcance de resultados satisfatórios?

\section{SUGESTÃO PARA ELABORAÇÃO DE PLANO DE ENSINO}

Sugere-se ao professor trabalhar este Caso de Ensino primeiramente a partir de sua leitura em sala de aula. Em seguida, ele deve realizar uma dinâmica de grupo.

Os alunos devem se dispor em sala formando dois círculos, sendo um maior, externo, e um menor, interno. O círculo interno fica estático, enquanto o círculo externo se move para a esquerda. A cada giro, os alunos ficam frente a frente, devendo, assim, debater entre si as questões para discussão supracitadas. Quando o círculo externo voltar à posição inicial, todos retornam a suas cadeiras e discutem abertamente sobre o assunto.

\section{REFERENCIAL TEÓRICO E ANÁLISE DO CASO}

Este Caso de Ensino defende, logo no início, na Introdução, que o aumento significativo da produção de bens de consumo nos últimos anos trouxe consigo o aumento também significativo da geração de resíduos sólidos, destinados, na maior parte das vezes, de maneira indevida, agressiva ao meio ambiente. Tal colocação pode ser discutida em sala de aula em comparação com os fatos apresentados no documentário "Uma verdade inconveniente", protagoni- 
zado pelo ex-vice-presidente norte-americano Al Gore, em 2006.

Segundo este Caso de Ensino, tal problema culminou na sanção da Lei 12.305/2010 (BRASIL, 2010), que instituiu a Política Nacional de Resíduos Sólidos que, ao estabelecer responsabilidades compartilhadas pelo ciclo de vida dos produtos entre fabricantes, distribuidores, comerciantes, consumidores e poder público, vem gerando diversos impactos na dinâmica socioeconômica do setor de reciclagem.

Duas abordagens lidam com a relação entre marco regulatório e firma. A primeira apresenta um trade-off entre preservação ambiental e competitividade empresarial e a segunda afirma que as empresas podem responder às restrições impostas pela regulação com inovações, reestabelecendo seus padrões de competitividade.

Trata-se, portanto, da questão da intervenção do Estado na economia, tema central do liberalismo econômico desde a publicação do livro "A riqueza das nações", de Adam Smith, e que perpassa toda a tradição da economia clássica e neoclássica até chegar aos dias de hoje. Mais recentemente, tal discussão pode ser pautada, principalmente no âmbito da estratégia empresarial, pela Hipótese de Porter que defende a inovação como uma forma de reestabelecimento da competitividade perante a regulação estatal.

O Caso de Ensino prossegue apresentando o Brasil como um país intermediário em comparação ao restante do mundo, no tocante à preservação do meio ambiente e, então, apresenta exemplos de práticas empresariais sustentáveis que, em sala de aula, podem ser pretextos para discussões sobre teorias referentes à Responsabilidade Socioambiental e ao Desenvolvimento Sustentável.
A Branca Recicláveis, empresa que protagoniza este Caso de Ensino, é, enfim, apresentada em detalhes, primeiramente com destaque para seus recursos internos e suas competências essenciais, bastante focados na fidelização de fornecedores. Em seguida, apresentam-se os desafios de mercado enfrentados pela empresa:

a) fornecedores buscando eliminar atravessadores;

b) baixa produtividade da força de trabalho;

c) redução da demanda e preços ditados pelos clientes;

d) aumento da concorrência e de sua competitividade e;

e) legislação alheia aos seus dilemas.

As estratégias competitivas da empresa para lidar com tais desafios de mercado são, então, apresentadas; na verdade, resumem-se a alavancar o negócio a partir de capital de terceiros, utilizados nas seguintes iniciativas:

a) cobrir prejuízos acumulados;

b) prospectar novos clientes;

c) adquirir ativos imobilizados para aumentar a capacidade produtiva e;

d) financiar pesquisa sobre a concorrência.

As iniciativas, no entanto, mostram-se sem aderência à atual dinâmica do setor, trazendo resultados insatisfatórios:

a) dificuldades de honrar compromissos financeiros;

b) distância geográfica significativa dos clientes que melhor remuneram;

c) quedas sucessivas nas aquisições de materiais recicláveis;

d) aumento da ociosidade produtiva das instalações e;

e) redução da competitividade em comparação com sucateiros me- 
lhor adaptados às mudanças do mercado.

Tais questões podem ser diretamente debatidas à luz de teorias e ferramentas como Gestão Estratégica, Forças de Porter, Análise SWOT, dentre outras.

\section{REFERÊNCIAS}

\section{BANCO DO NORDESTE. Programa} de Financiamento à Sustentabilidade Ambiental - FNE verde. Disponível em: $<$ http://www.banconordeste.gov.br/content/aplicacao/produtos_e_servicos/programas_fne/gerados/fne_verde.asp $>$. Acesso em: 27 ago. 2014.

BARBOSA, Vanessa. Brasil recicla 2,1 milhões de latinhas de alumínio por hora. Revista Exame Online, Rio de Janeiro, 31 out. 2012. Disponível em: <http://exame. abril.com.br/mundo/noticias/brasil-bate-recorde-em-reciclagem-de-latinhas-de-aluminio/>. Acesso em: 19 abr. 2014.

BRASIL. Lei $n^{\circ} 12.305$, de 2 de agosto de 2010. Institui a Política Nacional de Resíduos Sólidos; altera a Lei n⿳⺈-9.605, de 12 de fevereiro de 1998 e dá outras providências. Diário Oficial da União, Brasília, DF, 3 ago. 2010. Disponível em: <http:// www.planalto.gov.br/ccivil_03/ato20072010/2010/1ei/112305.htm>. Acesso em: 26 ago. 2014.

Secretaria de Assunto Estratégicos (SAE) . Nova Classe Média Brasileira assume o protagonismo. Brasília, DF: SAE, 2012. Disponível em: <http://www.sae.gov. br/novaclassemedia/wpcontent/uploads/ NewsletterDataPopularEdicaoNumerolok. pdf>. Acesso em: 19 abr. 2014.

. Ministério do Trabalho e Emprego.

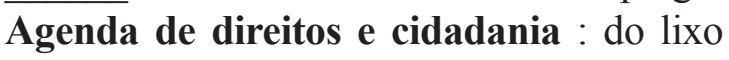
aos resíduos sólidos. Disponível em: $<$ http:// portal.mte.gov.br/data/files/8A7C816A3ADC4075013AFEED37B03643/RES\%C3\%8DDUOS $\% 20 \mathrm{~S} \% \mathrm{C} 3 \% 93$ LIDOS $\% 20$ 20mar12.pdf>. Acesso em: 27 ago. 2014.

CALDAS, Wânia. A riqueza que vem da cadeia produtiva do lixo. O Povo on line, Fortaleza, 26 jul. 2008. Disponível em: $<$ http://www.gvces.com.br>. Acesso em: 18 abr. 2014.

COMPANHIA DE ENERGIA ELÉTRICA DO ESTADO DO CEARÁ (COELCE). Ecoelce: 6 anos de benefícios para a população cearense. Disponível em: <https:// www.coelce.com.br/ coelcesociedade/programas-e-projetos/ecoelce.aspx>. Acesso em: 18 abr. 2014.

DEMAJOROVIC, J.; MIGLIANO, J. E. B. Política Nacional de Resíduos Sólidos e suas implicações na cadeia de valor da logística reversa de microcomputadores no Brasil. Revista Gestão \& Regionalidade, São Paulo, v. 29, n. 87, set./dez. 2013.

HEBER, Florence; SILVA, Elvis Moura da. Institucionalização da Política Nacional de Resíduos Sólidos: dilemas e constrangimentos na Região Metropolitana de Aracaju (SE). Revista de Administração Públi- 
ca, Rio de Janeiro, v. 48, n. 4, p. 913-937, jul./ago. 2014.

LEITE, Paulo Roberto. Logística reversa: meio ambiente e competitividade. São Paulo: Prentice Hall, 2003.

MAIA, Samantha. Quem paga a reciclagem? Na Europa são as empresas. No Brasil, o governo e o setor privado não se entendem. Revista Carta Capital on line, São Paulo, nov. 2013. Disponível em: $<$ http://www.cartacapital.com.br/revista/774/ quem-paga-a-reciclagem-5951.html>. Acesso em: 18 abr. 2014.

MARCHI, C. M. D. F. Cenário mundial dos resíduos sólidos e o comportamento corporativo brasileiro frente à logística reversa. Perspectivas em Gestão \& Conhecimento, João Pessoa, v. 1, n. 2, p. 118-135, jul./ dez. 2011.

PORTAL BRASIL. Reciclagem atinge apenas $8 \%$ dos municípios brasileiros. 13 abr. 2012. Disponível em: <http://www. brasil.gov.br/meio-ambiente/2012/04/reciclagem-atinge-apenas-8-porcento-dos-municipios-brasileiros $>$. Acesso em: 19 abr. 2014.

SINDICADO DAS EMPRESAS DE RECICLAGEM DE RESÍDUOS SÓLIDOS DOMÉSTICOS E INDUSTRIAIS NO ESTADO DO CEARÁ (Sindiverde). O lugar de lixo é na reciclagem. Disponível em: <http://www.fiec.org.br/portalv2/sites/ sindverde/home.php?st=noticias\&conteudo_id=28040>. Acesso em: 12 out. 2013.

SOUZA, M. T. S.; PAULA, M. B.; SOUZA, P. H. O papel das cooperativas de reciclagem nos canais reversos pós-consumo. Revista de Administração de Empresas, São Paulo, v. 52, n. 2, p. 246-262, 2012. 